\title{
Educators dissect the future of medical training
}

NEW YORK-Today's medical students carry vast amounts of reference materials on their iPhones and laptops. They're increasingly likely to learn anatomy with a computer in place of a scalpel. And when they graduate, they'll be seeing patients who've had genetic testing to determine disease risk. So how do medical schools adjust their curricula to cope with these twenty-first century realities?

Medical educators gathered at the New York Academy of Sciences earlier this summer to hash out answers to this question at a forum titled "Innovating and Updating the Medical School Curriculum." At the meeting, Carol Storey-Johnson, a dean of education at the Weill Cornell Medical College in New York, talked about the need to integrate scientific coursework and clinical training throughout medical school. Charles Weiner, vice-chairman of education at the Johns Hopkins School of Medicine in Baltimore, expanded on efforts to merge these areas in a presentation on his institution's new curricular model, "Genes to Society," which emphasizes a view of disease tuned to individual variability.

According to educators at the meeting, the use of computer-assisted simulations will continue to grow exponentially in medical education-whether through the use of three-

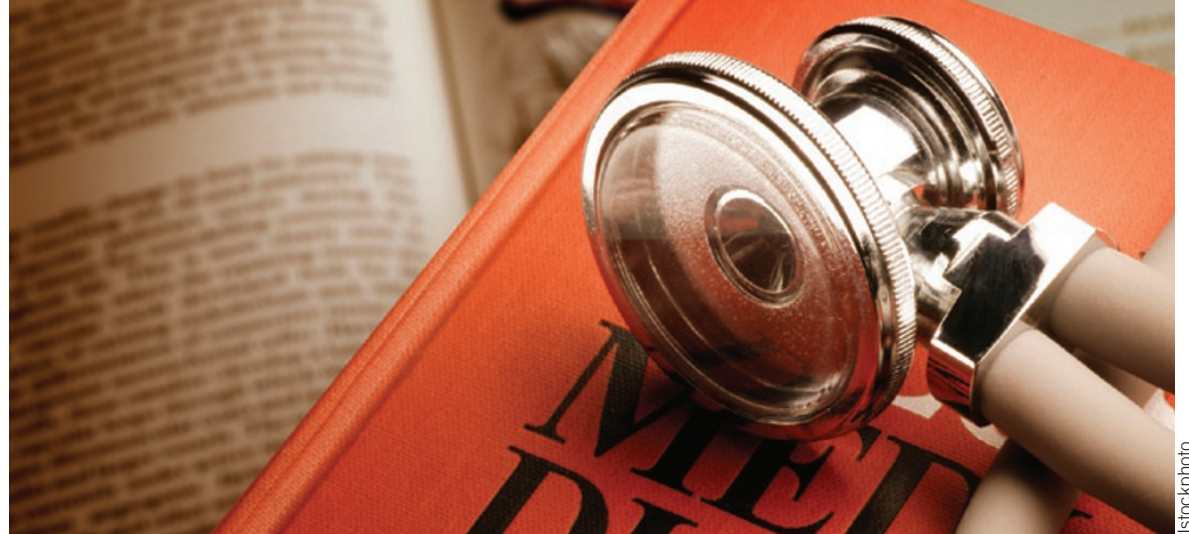

Finger on the pulse: Medical educators adapt to new technologies.

dimensional anatomical models or through robotic patients. Hands-on cadaver dissections will soon no longer be a common staple of the first-year medical school experience; they're being replaced by dissection demonstrations and fixed-tissue specimens.

The shift away from cadaver dissections is attributed to a lack of bodies rather than a conscious philosophical shift. Fewer people are donating their remains to medicine, research money devoted to anatomy is becoming a scarce commodity and the number of anatomists is dwindling to an aging few.
There was a palpable sense of regret among conference goers that future generations of doctors wouldn't go through the familiar rite of passage.

Others took a matter-of-fact view of the disappearance of cadaver dissections. "I used to feel the same way about the light microscopes, when they got rid of those," Helen Shields, a gastroenterologist at Beth Israel Deaconess Medical Center in Boston, told Nature Medicine. "But the students are doing just fine without them."

Roxanne Palmer

\section{Teaching hospitals urged to disclose clinical conflicts of interest}

Say you need a hip replacement. If your doctor at the large, well-reputed university hospital recommends a particular brand of artificial hip that he happened to invent, and therefore might be collecting royalties on, should he be required to tell you? The Association of American Medical Colleges (AAMC) thinks so. In late June, the AAMC issued a report recommending that teaching hospitals establish mechanisms to disclose any ties to industry that their physicians have that could potentially have an impact on their clinical practice.

"Many medical centers have conflictof-interest policies that govern research and corporate relations; however, less than one percent have adopted policies that define conflict of interest in clinical care," AAMC chief medical officer Joanne Conroy said in a 30 June teleconference with members of the press.

One of the members of that one percent is the Washington University School of Medicine (WUSM) in St. Louis, which adopted a stringent clinical conflict-ofinterest policy in 2006. Under these rules, doctors must disclose potential financial conflicts of interest to the university, which publishes information on any industry relationship that nets a physician more than $\$ 10,000$ annually on its medical practice website.

Before recommending the use of an implantable medical device, physicians have to inform the patient if they have a relationship to the manufacturer. In some cases, ties to pharmaceuticals or other products must also be disclosed. Furthermore, doctors at WUSM cannot receive any royalties from devices, drugs or any other medical care product used on WUSM patients (even if the device is recommended by another doctor). Those that fail to comply with the policy can have their clinical privileges suspended, professional liability insurance coverage withdrawn and salary or bonus reduced.

"Academic institutions should be leaders in ensuring professional integrity and preserving public trust," says WUSM vice chancellor James Crane, the architect of the clinical conflict of interest policy.
"We are also entrusted with educating future generations of physicians, and it is important that our faculty serve as role models for those we train."

The AAMC's guidelines don't go so far as to recommend prohibiting the collection of royalties but suggest that hospitals make good faith efforts to let patients know their doctor could benefit financially from prescribing a particular method of care. It's up to the institution to decide how to handle disclosure. That could mean publishing the information on a website or disclosing the information to the patient when they register at the hospital. But the guidelines do not aim to discourage doctors from working with commercial health care companies.

"Partnerships between academic medical centers and industry are essential to medical innovation and create powerful collaborations that benefit patients," Conroy said. "It's not the conflict itself; it's really the management of that conflict." Roxanne Palmer 